\title{
Structure of Axon Terminals and Active Zones at Synapses on Lizard Twitch and Tonic Muscle Fibers ${ }^{1}$
}

\author{
J. P. WALROND ${ }^{2}$ AND T. S. REESE
}

Laboratory of Neurobiology, National Institute of Neurological Diseases, Communicative Disorders and Stroke, National Institutes of Health at the Marine Biological Laboratory, Woods Hole, Massachusetts 02543

\begin{abstract}
The freeze-fracture technique was used to study differences in membrane structure which could explain differences in the number of quanta released from axon terminals on twitch and tonic muscle fibers in Anolis intercostal muscles. The protoplasmic leaflets of axon terminals facing lizard twitch muscle fibers have intramembrane particle specializations characterized by two parallel linear particle arrays each composed of two particle rows which lie perpendicular to the axis of shallow ridges in the axolemma. During $\mathrm{K}^{+}$ depolarization, vesicles open between the arrays, confirming that these structures are the active zones for synaptic vesicle opening. Active zones at axon terminals on tonic fibers are defined by one linear particle array composed of two parallel particle rows oriented along the axis of a shallow presynaptic ridge; vesicles open beside these arrays. Thus, there are more particles near active zone vesicles in terminals on twitch fibers. Even though terminals on twitch and tonic muscle fibers seem to have similar numbers of synaptic vesicles associated with their active zones, a presynaptic action potential is reported to release at least $\mathbf{1 0}$ times more quanta from terminals on twitch fibers. We postulate that the differences in quantal output are related to the observed differences in the number of active zone particles flanking synaptic vesicles at the active zone. Indeed, the correlation between the distribution of these particles and the level of transmitter release provides additional support for the idea that they are the calcium channels which couple transmitter release to the action potential.
\end{abstract}

Quantal neurotransmitter release at the neuromuscular junction occurs when synaptic vesicles fuse with the presynaptic plasma membrane at discrete sites known as active zones (Couteaux and Pecot-Dechavassine, 1970, 1974; Ellisman et al., 1976; Wernig, 1976). It is generally accepted that the active zones occupy only a small proportion of the area of the nerve terminal tacing the muscle (Couteaux and Pecot-Dechavassine, 1970, 1974; Heuser et al.,

Received May 14, 1984; Revised October 26, 1984;

Accepted November 8, 1984

${ }^{1}$ We would like to thank Dr. R. M. Llinás for the discussions of our model formulating how the distribution of a small number of $\mathrm{Ca}^{2+}$ channels might influence transmitter release. Dr. A. Steinacker introduced us to the lizard intercostal muscle preparation, Dr. E. F. Nemeth reviewed the manuscript, and Janet Kinnane provided expert photographic assistance. J. P. W. was supported in part by a fellowship from the Muscular Dystrophy Association of America.

${ }^{2}$ To whom correspondence should be addressed.
1974) and that the vesicles which open at these sites are drawn from a small subpopulation of synaptic vesicles already lined up at the presynaptic membrane (Couteaux and Pecot-Dechavassine, 1970 1974; Heuser and Reese, 1973).

Freeze-fracture views of active zones at central and peripheral synapses have demonstrated that aggregates of large intramembrane particles are found beside synaptic vesicle openings (Akert et al., 1972; Peper et al., 1974; Ellisman et al., 1976; Venzin et al., 1977; Pumplin and Reese, 1978; Ceccarelli et al., 1979; Heuser et al., 1979; Heuser and Reese, 1981; Dickinson-Nelson and Reese, 1983). These observations have led to the suggestion that the active zone particles might be calcium channel complexes through which calcium enters the axon terminal to initiate neurotransmitter release (Heuser et al., 1974; Pumplin et al., 1981).

Although the details of active zone organization are different at neuromuscular junctions in various vertebrates and invertebrates (Ellisman et al., 1976; Franzini-Armstrong, 1976; Rheuben and Reese, 1978; Govind et al., 1982; Verma and Reese, 1984), no obvious pattern has yet emerged to explain the functional bases of these differences. To understand better the functional significance of this structural variability, we examined synapses on physiologically distinct muscle fiber types from an Anolis lizard intercostal muscle.

Lizard intercostal muscles contain twitch and tonic muscle fibers. We have chosen to use the term "tonic" rather than "slow" to avoid confusion with slow muscle fibers in mammals which, except for extraocular muscles, intrinsic muscles of the ear, and a few muscles in the esophagus, are in fact twitch fibers (Morgan and Proske, 1984). In reptiles, twitch fibers are focally innervated and conduct action potentials, whereas tonic muscle fibers are multiterminally innervated and do not conduct action potentials (Proske and Vaughn, 1968; Ridge, 1971; Morgan and Proske, 1984). Because the twitch fiber response is all or none, synaptically activating one of these fibers requires that a presynaptic action potential release sufficient neurotransmitter to bring the muscle fiber to threshold. In tonic fibers, however, postsynaptic potentials are graded, and the level of depolarization in the muscle fiber depends on the number and frequency of action potentials in the presynaptic cell (Proske and Vaughn, 1968; Ridge, 1971; Morgan and Proske, 1984). A presynaptic action potential releases at least 10 times more quanta from an axon terminal on a twitch fiber than from one on a tonic fiber (Proske and Vaughn, 1968; Ridge, 1971; Hartzell et al., 1975; Dionne and Parsons, 1981). The present study uses freeze-fracture techniques to investigate the relationship between the structural organization of the active zone and the difference in quantal output from axon terminals on twitch and tonic muscle fibers.

\section{Materials and Methods}

Animals. Adult Anolis lizards (Carolina Biological Supply) were maintained in a terrarium, fed crickets three times a week, and provided heat and light from a $60-\mathrm{W}$ bulb for $14 \mathrm{hr}$ each day. Before fixation, two sets of nine ribs were removed from a decapitated animal, immersed in a dish of physiological 

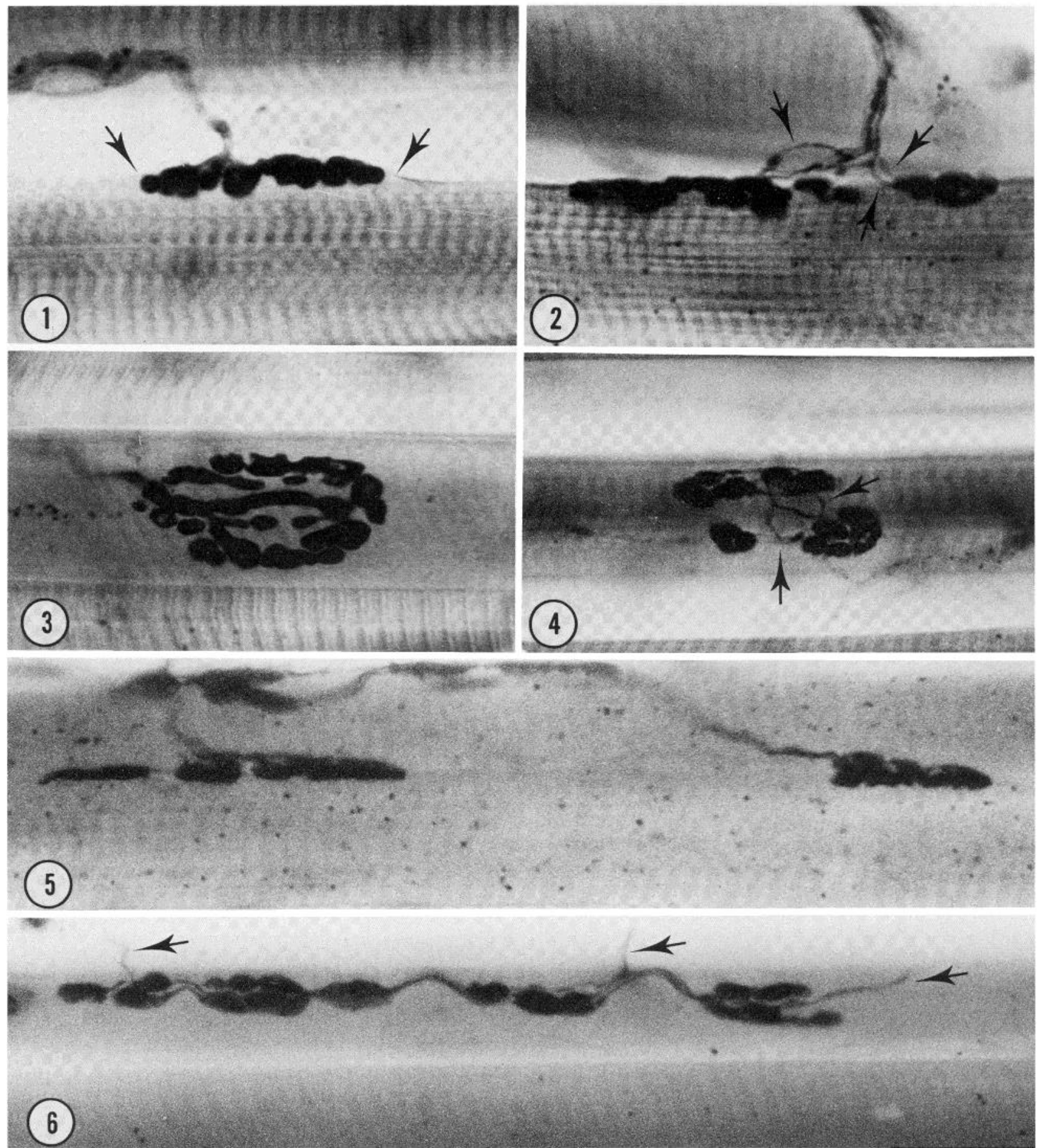

Figures 1 to 6 are from muscles stained with zinc iodide and shown at a magnification of $\times 1,600$.

Figure 1. Edge-on view of a typical endplate on a singly innervated fiber. A single axon gives rise to a single cluster of boutons which sits in a crater-like depression in the sarcolemma. The rim of the crater (arrows) is elevated above the plane of the muscle fiber membrane.

Figure 2. Edge-on view of several clusters of axonal boutons on a diffusely innervated fiber. Several tiny nerve fibers (arrows) terminate in separate, individual or small clusters of boutons which lie nearly flush with the sarcolemma (Fig. 8 shows that these may be single axons).

Figure 3. En face view of an endplate on a singly innervated fiber. The interconnected boutons appear to be varicosities along terminal branches of a single axon.

Figure 4. En face view of one of several clusters of axonal boutons on a diffusely innervated fiber. Several tiny axons coursing along the surface of the muscle interconnect clusters of boutons (arrows).

Figure 5. Two clusters of axonal boutons, showing the pattern typical of multiple innervation. Isolated clusters receive input from separate nerve branches.

Figure 6. Example of multiple innervation where borders between separate axonal clusters are not clear, presumably because they overlap. However, two or three separate axons or axon bundles (arrows) contact this large cluster. 
saline (132 mM NaCl, $3.0 \mathrm{~mm} \mathrm{KCl}, 3.0 \mathrm{mM} \mathrm{CaCl}_{2}, 0.5 \mathrm{mM} \mathrm{MgCl}, 5.0 \mathrm{~mm}$ glucose, and $5.0 \mathrm{~mm}$ HEPES, $\mathrm{pH} 7.2$ ), and maintained at rest at room temperature. Small volumes ( $1 \mathrm{~mm}$ deep) were used to permit diffusion of oxygen to the muscle.

Light microscopy. A zinc iodide solution was made by suspending $3 \mathrm{gm}$ of zinc dust in $40 \mathrm{ml}$ of water and slowly adding $1 \mathrm{gm}$ of iodine to the suspension (Akert and Sandri, 1968; McMahan and Kuffler, 1971). Intercostal muscles were immersed in a $0.5 \%$ solution of osmium tetroxide, which had been diluted from $2.0 \%$ with a portion of the filtered zinc iodide solution, and were left overnight in a light-tight container. Stained muscles were dehydrated through an ethanol series, cleared in xylene, dissected free of ribs, and mounted in Permount. Other muscles were stained for esterases to visualize synaptic basal laminas (Tsuji, 1974)

Thin sectoin electron microscopy. Muscles were fixed in $3 \%$ glutaraldehyde, $2 \%$ paraformaldehyde, and $1 \%$ acrolein in $0.1 \mathrm{M}$ cacodylate buffer (pH 7.2) containing $1.8 \mathrm{mM} \mathrm{CaCl}_{2}$ and $2.5 \%$ dimethylsulfoxide. After $1 \mathrm{hr}$ of fixation these muscles were washed in the buffer solution and postfixed in a solution containing $2 \%$ osmium tetroxide, $10 \mathrm{mM} \mathrm{CaCl}_{2}$, and $3 \%$ potassium ferrocyanide in $50 \mathrm{~mm}$ cacodylate buffer ( $\mathrm{pH} 7.2$ to 7.5 ) at room temperature.

Frcezo fracture clcctron microscopy. A set of eight intercostal muscles was immersed in physiological saline containing $2.5 \%$ glutaraldehyde and in some instances, $1 \%$ acrolein. After 30 min of fixation, the tissue was processed through a graded glycerol series up to $30 \%$ in water. Pieces of the intercostal muscles containing one fiber layer were then removed from the ribs, sandwiched between two gold specimen carriers which had been coated with a thin layer of $30 \%$ polyvinyl alcohol in a $25 \%$ glycerol/water solution (Cohen and Pumplin, 1979), and frozen by immersing in liquid Freon 22. Frozen specimens were placed in a double replica device and freezefractured between 152 and $163^{\circ} \mathrm{K}$ in a Blazer's 360 or 301 freeze-fracture apparatus. immediately after fracturing, the specimens were unidirectionally shadowed from $45^{\circ}$ with 1.5 to $2.0 \mathrm{~nm}$ of platinum followed by carbon. Replicas were floated on household bleach to separate them from the underlying tissue.

To increase quantal transmitter release and the number of exocytotic pits observed in freeze-fracture views, axon terminals were depolarized in high $\mathrm{K}^{+}(20 \mathrm{~mm})$ physiological saline for $5 \mathrm{~min}$ before fixing with $4 \%$ paraformaldehyde in high $\mathrm{K}^{+}$saline. Paraformaldehyde was used because it increases the number of exocytotic pits captured by the fixative (Heuser et al., 1974). Control preparations were fixed in $4 \%$ paraformaldehyde in normal saline. Following these procedures, experimental and control specimens were prepared for freeze-fracture as described above.

\section{Results}

Organization of the intercostal system. The Anolis lizard has eight intercostal muscles on each side. Muscles connecting adjacent ribs are one or two fibers thick. The muscles dorsal to the lateral line are two layers thick and run obliquely to each other, but ventral to the lateral line the intercostal muscle is only a single layer of muscle fibers; neuromuscular junctions on these ventral muscles are the subject of this study.

Zinc iodide-osmium $(\mathrm{ZIO})$ staining reveals the innervation of these muscles. The nerves which innervate intercostal muscles course along each rostral rib and extend branches caudally onto the muscles where they further arborize and synapse with individual muscle fibers. A few muscles may receive innervation from the next caudal nerve. Individual muscle fibers may be focally or diffusely innervated. The synaptic boutons on focally innervated muscles arise from a single nerve branch and are nestled in a crater-like depression which is elevated above the plane of the muscle mem- brane (Fig. 1). The tightly packed boutons (Fig. 3) are in fact varicosities on the terminal branches of a single axonal process.

Diffusely innervated fibers typically have compact clusters of axon terminals at intervals along their lengths (Figs. 2 and 4 to 6). These clusters arise from multiple fine axon branches or bundles of axons. Each branch forms only a few boutons, but further branches also course along the muscle cell surface to give rise to other clusters of terminals (Fig. 5). Terminals on other diffusely innervated fibers were scattered for long distances along the surface of the muscle fiber (Fig. 6). Whether these two classes of synaptic organization correspond to two functionally distinct classes of diffusely innervated muscle fiber remains to be determined. It is also unclear from the zinc iodide stains how many separate axons innervate the diffusely innervated fibers

Synapses on diffusely and on focally (singly) innervated fibers were identified in whole mounts of muscles stained tor cholinesterase and then thin sectioned to determine differences in their ultrastructure. The synaptic boutons on singly innervated fibers are nestled in the primary fold and face numerous invaginations of the sarcoplasm known as secondary folds. The secondary folds proved useful for identifying muscle fiber type and therefore axon terminal type in freeze-fracture replicas. A Schwann cell process always caps the nerve terminal where it is not next to the muscle (Fig. 7). The axon terminals on diffusely innervated fibers sit in shallow primary folds (Fig. 8), whose sides are formed by a postsynaptic sarcolemmal ridge which partially envelopes the bouton. Secondary folds on tonic fibers form shallow ridges that are less pronounced than those on twitch fibers. A Schwann cell process covers that portion of the terminal which protrudes above the ridge. Mitochondria and scattered cytoskeletal elements reside primarily in the protruding portion of the terminal, whereas the synaplic vesicles lie within the region bounded by the sarcolemmal ridge. These boutons are frequently accompanied by single unmyelinated axons (Fig. 8), which shows that some of the axon processes observed in whole mounts (Figs. 2 and 4 to 6 ) are likely to be individual axon branches.

Cross-sections through the muscle cells underlying these terminals show that singly innervated fibers have smaller myofibrillar bundles and more sarcoplasmic reticulum than do diffusely innervated fibers (Figs. 7 and 8 ). Longitudinal sections through diffusely innervated fibers also showed jagged $Z$ lines and faint $M$ bands, whereas singly innervated fibers had straight $Z$ lines and clearly discernible $M$ bands (Figs. 9 and 10). These characteristics allow us to designate confidently the singly innervated fibers as twitch and the diffusely innervated fibers as tonic on the basis of distinctions already established for frog and snake muscle fibers (Hess, 1965; Page, 1965; Morgan and Prosko, 1984).

Freeze-fracture. Axon terminals on twitch fibers can be distinguished from those on tonic fibers in freeze-fracture replicas by the size and shape of the sarcolemmal infoldings that form the postsynaptic junctional folds (Fig. 11). The P (protoplasmic) face of axon terminals on twitch fibers is marked by paired linear particle arrays. Each member of the pair consists of two rows of particles situated on the crests of vaguely defined shallow ridges (Figs. 12 and 14). The ridges lie in register with the gaps between adjacent junctional folds, and the particle arrays are typically oriented perpendicular to the axis of these ridges (Fig. 13). Occasionally, when the plane of

Figure 7. Thin section through a cholinesterase-stained endplate on a singly innervated fiber. The boutons nestle in deep infoldings of the muscle membrane the sides of which stand up above the surface of the muscle fiber. Esterase reaction product marks the primary synaptic cleft, separating the bouton and the secondary junctional folds. Esterase reaction product also marks the secondary synaptic clefts between the folds but is less intense where the nerve is not apposed to muscle (arrow near bouton on right). The abundant sarcoplasmic reticulum divides the muscle fiber into regularly spaced fibrils typical of twitch fibers. Magnification $\times 27,000$

Figure 8. Thin section through esterase stained axon terminals on a multiply innervated fiber. A rim of sarcolemma defines a flat synaptic cleft containing esterase stain. The rim only partially envelopes the bouton and the remainder is covered by a Schwann cell process. Nonmyelinated processes $(A)$ presumably tiny preterminal axons (see Fig. 4), frequently accompany these terminals. The muscle fiber contains large myofibrils separated by sarcoplasmic reticulum; this organization is characteristic of tonic muscle fibers. Magnification $\times 27,000$. 

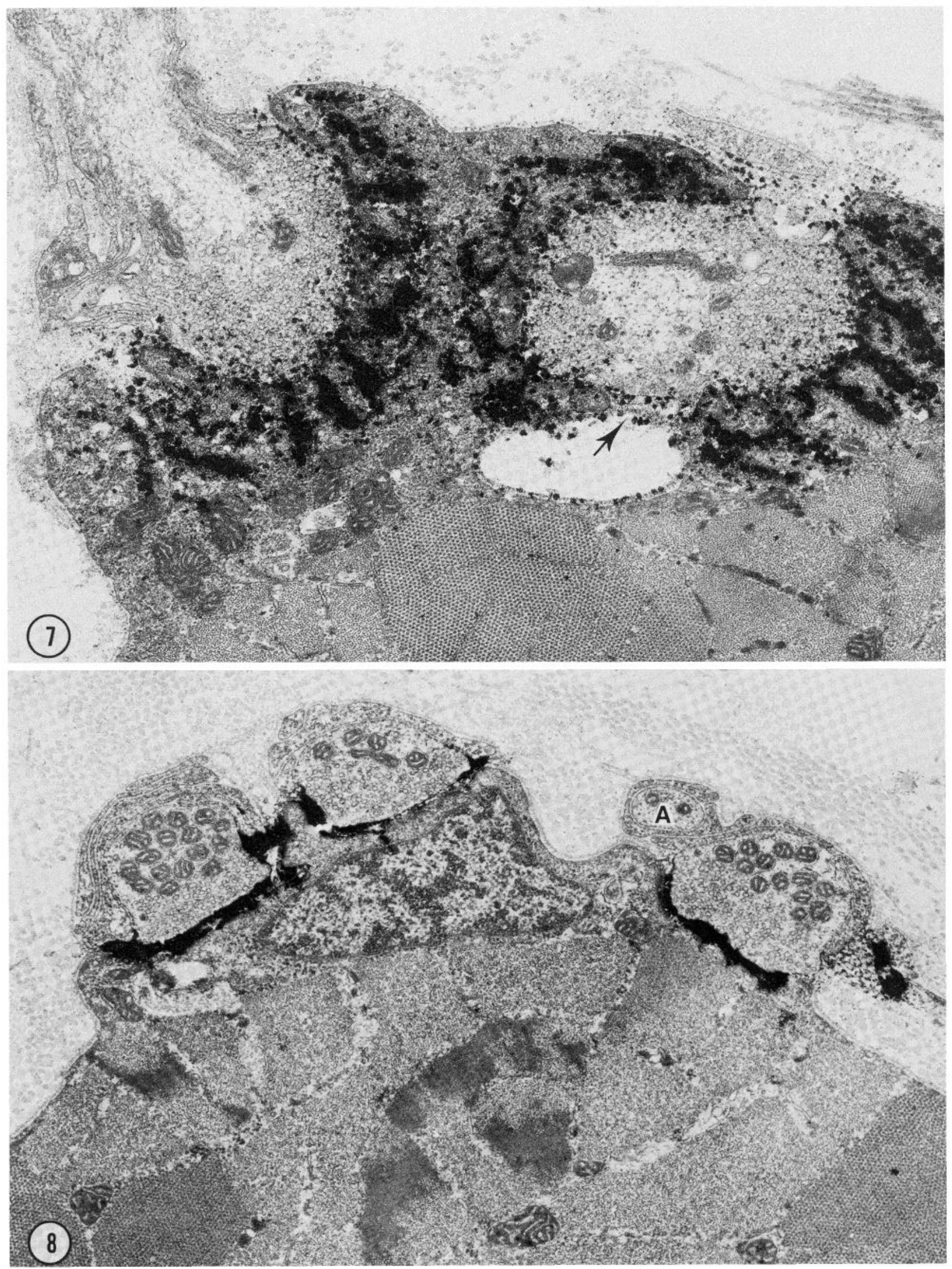

Figures $7-8$ 

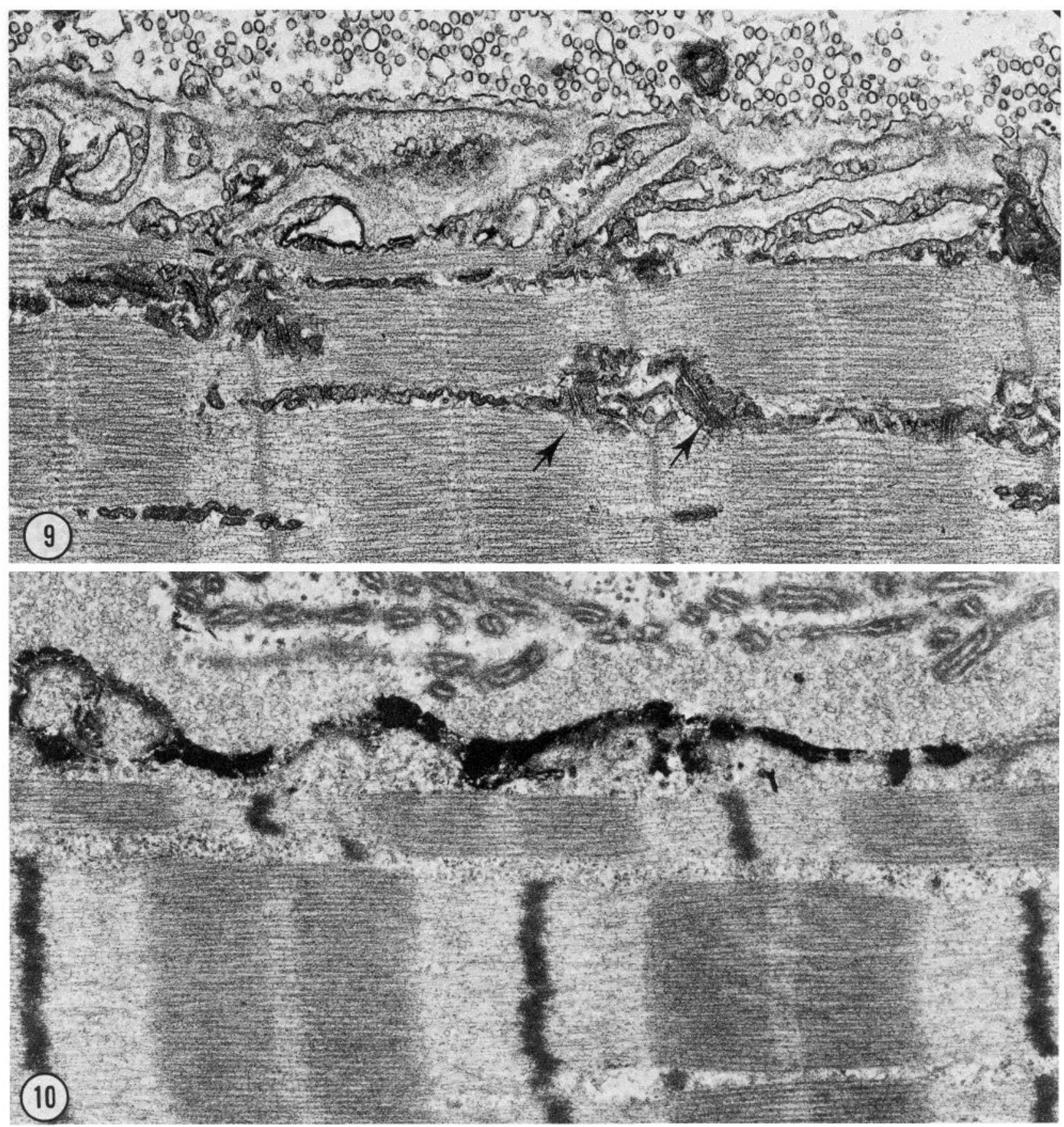

Figure 9. Longitudinal section through an axon terminal on a twitch fiber. These muscle fibers are identified by their straight $\mathrm{Z}$ lines, distinct $\mathrm{M}$ bands, and deep postsynaptic folds. Triads, where the T tubule meets the sarcoplasmic reticulum, are evident at the A-I junction (arrows). Conventional fixation. Magnification $\times 35,000$.

Figure 10. Longitudinal section through an esterase-stained axon terminal on a tonic fiber. Broad, wavy $\mathrm{Z}$ lines, indistinct $\mathrm{M}$ bands, and long sarcomeres identify these fibers as tonic. Folding of the postsynaptic membrane is much less prominent. Magnification $\times 35,000$.

Figure 11. Freeze-fractured terminal on a twitch fiber identified by the deep junctional infoldings $(F)$ which envelope the terminal except where it is capped by a Schwann cell process $(s)$. A cross-fracture through the terminal reveals synaptic vesicles $(v)$, mitochondria $(m)$, and microtubules (arrows). Magnification $\times 19,000$

Figure 12. Enlargement of the left side of Figure 11. The $\mathrm{P}$ face of the axon terminal has short linear particle arrays which tend to lie perpendicular to the axis of shallow synaptic ridges (arrows). Each array contains two parallel particle rows. Magnification $\times 37,000$.

Figure 13. Tracing of Figure 12. Each short white line represents a linear particle array; pairs of white lines indicate positions of the paired linear arrays (see Fig. 25). Separate paired arrays tend to be parallel to one another when they lie along the same low ridge. Magnification $\times 37,000$.

Figure 14. Detail of paired linear particle array. Individual particles are uniform in size and larger than surrounding particles. Magnification $\times 195,000$.

Figure 15. Cross-fracture showing relationship of a linear particle array (arrowhead) to synaptic vesicles (v) inside the terminal. A synaptic vesicle lies closely apposed to the plasmalemma beside a linear particle array; it is presumably these vesicles which form vesicle openings (see Figs. 20 and 25 ). Magnification $\times 195,000$ 

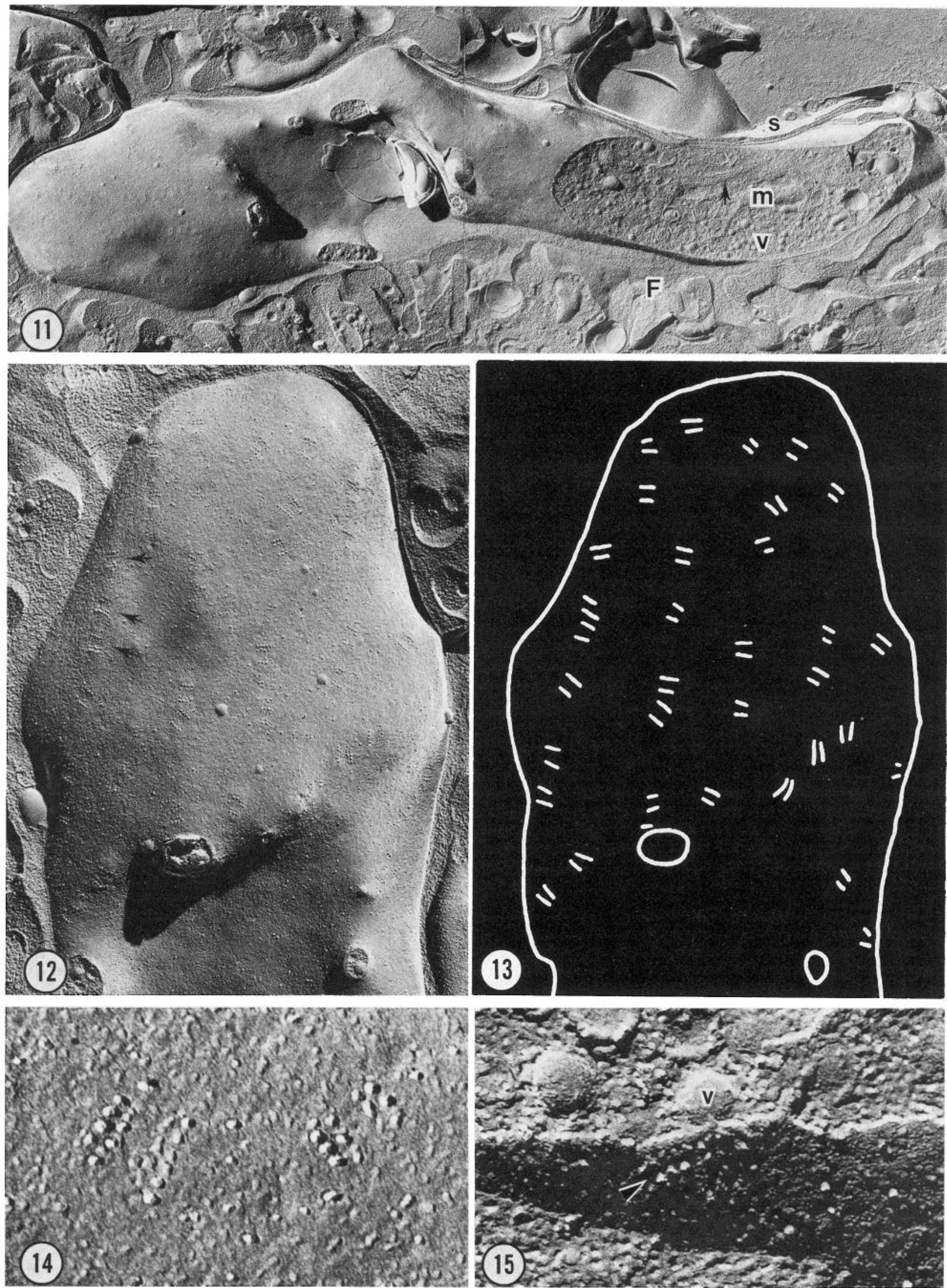
fracture passes through the cytoplasm, a synaptic vesicle can be seen closely apposed to the plasma membrane near the particle array (Fig. 15).

The axon terminals on tonic muscle fibers can be recognized in freeze-fracture replicas by the characteristic shape and size of the sarcolemmal infoldings that form the postsynaptic junctional folds and the linear particle arrays in the protoplasmic leaflets of the axon terminal. Linear particle arrays composed of two parallel particle rows lie along vaguely defined ridges in the axon terminal and tend to be oriented paraliet rather than perpendicular to the axis of the ridge (Figs. 16 to 18). These linear arrays vary in length (Fig. 19) but seem to end when they approach the brink of the ridge (Fig. 16).

Stimulation experiments. Synaptic vesicle opening was evoked by immersing muscles on their ribs in physiological saline containing $20 \mathrm{mM} \mathrm{K}^{+}$and $4 \%$ paraformaledhyde to determine the relationship between synaptic vesicle openings and the linear particle arrays found on the $P$ face of the axon terminal. The high concentration of $\mathrm{K}^{+}$was expected to depolarize the terminals and increase the quantal release of acetylcholine above resting levels (Heuser et al., 1974; Ceccarelli et al., 1979). Views of membrane faces of synaptic terminals revealed large pits in the protoplasmic leaflets (Figs. 20 and 21) which are characteristic of synaptic vesicle openings (Heuser ct al., 1974; Ellisman ct al., 1976; Ceccarelli et al., 1979; Heuser et al., 1979). At axon terminals on twitch fibers, one or two synaptic vesicle openings typically lie between two parallel linear particle arrays. At axon terminals on tonic muscle fibers, single vesicle openings appeared beside unpaired linear particle arrays (Fig. 21). Thus, stimulation induccd vesiclc openings in axon terminals on both twitch and tonic muscle fibers are intimately associated with the linear particle arrays. In accordance with previous studies (Couteaux and Pecot-Deschavassine, 1970; Ellisman et al., 1976; Heuser and Reese, 1977), these regions will be referred to as active zones.

The position of exocytotic pits between the two linear particle arrays on twitch axon terminals means that a maximum of two vesicles could lie near the axolemma at these active zones because they are too short to accommodate any more. The variable length of the particle arrays on tonic axon terminals (45 to $220 \mathrm{~nm}$ ) means that 2 to 10 vesicles could lie near the axolemma at these active zones, but the actual number is uncertain because we were unable to determine whether vesicles line up on just one or on both sides of the active zone particles. We only found three instances in which two vesicle openings occurred beside an active zone at a tonic fiber, and in each instance both openings appeared on the same side of the particle array.

Thin sections through active zones in axon terminals on twitch fibers show vesicles apposed to the plasmalemma but separated from one another by a fuzzy projection contacting the presynaptic membrane (Fig. 20); the size and position of the bare region between the vesicle openings seen in freeze-fracture replicas correspond to the intracellular position of this fuzzy projection (Fig. 20). Thin sections through active zones on tonic fibers also show that synaptic vesicles are apposed to the membrane beside a dense projection. Although the dense projections and membrane-associated vesicles may be used to identify active zones in properly oriented thin sections, this type of view does not provide exact information about the locations of active zone particles relative to synaptic vesicies.

Active zones on twitch axon terminals have $17 \pm 4$ particles ( 370 active zones, Fig. 19) which are evenly distributed among four rows in two parallel linear particle arrays (Fig. 19, Table I). The center to center spacing of particles along the length of a row is $16.7 \pm 2.4$ $\mathrm{nm}$ and is $17.3 \pm 2.2 \mathrm{~nm}$ between the rows. The particles forming the two inner rows are separated by $37.5 \pm 3.3 \mathrm{~nm}$ (center to center). The $13 \pm 6$ particles (266 active zones) at active zones on tonic axon terminals (Fig. 19, Table I) are divided between two rows (i.e., one linear particle array). The rows of particles in the array are separated by $18.2 \pm 1.8 \mathrm{~nm}$, whereas the particles along the length of the row are separated by $16.1 \pm 3.6 \mathrm{~nm}$. Although the numbers of particles in the two types of active zone are not dramatically different, the number of particles per active zone associated with tonic fibers is more variable and presumably indicates a greater variability in the number of vesicles per active zone.

Since synaptic vesicles near the active zones may comprise the pharmacologicaly defined "readily releasable pool" of vesicles (Couteaux and Pecot-Deschavassine, 1970; Heuser and Reese, 1973), the number of vesicles in this position can provide a basis to predict the size of such a pool. Measurements of muscles stained with $\mathrm{ZIO}$ showed that twitch axon terminals cover $211 \pm 66 \mu \mathrm{m}^{2}(N=23)$ of muscle fiber surface, whereas tonic terminals cover $403 \pm 123 \mu \mathrm{m}^{2}$ $(N=10)$. These measurements yield only areas from aerial projections of axon terminals and therefore do not describe accurately the total area available for vesicle openings. A correction factor was obtained from thin sections by determining the ratio of the bouton perimeter facing the sarcolemma to the diameter of the bouton and correcting the aerial projection by multiplying it by this ratio. For terminals on twitch fibers, this ratio is $1.8 \pm 0.4(N=42)$, and for terminals on tonic muscle fibers it is $1.3 \pm 0.5(N=31)$. Therefore, the typical terminal area containing active zones on twitch fibers is $380 \pm 141 \mu \mathrm{m}^{2}$, whcrcas the corresponding area on tonic fibers is $524 \pm 257 \mu \mathrm{m}^{2}$ (Table I).

Counts of active zones per unit area in freeze-fracture replicas yielded the concentration of active zones in the presynaptic membrane. Axon terminals on twitch fibers contain $6.3 \pm 1.8$ active zones $/ \mu \mathrm{m}^{2}$; thus, a typical synapse on a twitch fiber contains 2,400 $\pm 1,100$ active zones. Since each active zone has a maximum of two vesicles intimately associated with it, these synapses are estimated to have 5,000 active zone-associated vesicles. Axon terminals on tonic fibers contain $3.4 \pm 1.1$ active zones $/ \mu \mathrm{m}^{2}$ and, therefore, contain $1,800 \pm 1,000$ active zones. Since the lengths of these active zones are variable (Fig. 19), an active zone facing a tonic fiber can contain between 1 and 10 vesicles. However, the shorter active zones are more common (Fig. 19); therefore, the number of active zone-associated vesicles in axon terminals on tonic muscle fibers is estimated to be either 5,000 or 10,000 vesicles, the higher number if vesicles line up on both sides of the linear array. Thus, the number of vesicles associated with active zones in terminals on tonic fibers is indistinguishable from the number on twitch fibers. The only distinct quantitative difference between active zones of terminals on the two types of muscle appears to be that terminals on twitch fibers have almost twice as many active zone particles (Table I). Indeed, the arrangement of active zone particles and their consequent position relative to the active zone vesicles provide the most dramatic structural difference between active zones facing twitch and tonic muscle fibers (see Fig. 25 and "Discussion").

Postsynaptic membrane. The three types of cells participating in a neuromuscular junction (Schwann cell, neuron, and muscle) are also evident in freeze-fracture replicas; therefore, the identification of the various fracture faces is unequivocal (Fig. 22). The $P$ face of the axon terminal, which lies directly beneath the Schwann cell, contains numerous particles. However, this region is devoid of the ridges and linear particle arrays characteristically found on the $P$

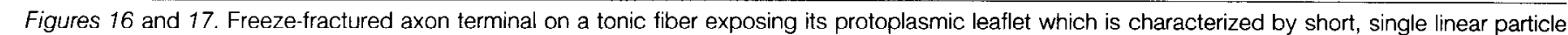

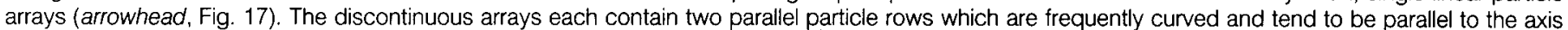

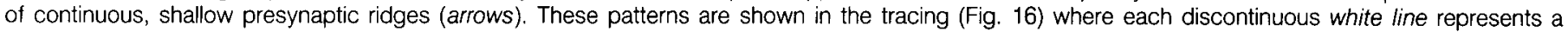
single array of $P$ face particlos. Magnification $\times 37,000$.

Figure 18. Three linear arrays (between arrowheads) which lie on a single ridge in a terminal on a tonic fiber (indicated by arrowhead in Figs. 16 and 17 ). Magnification $\times 195,000$. 

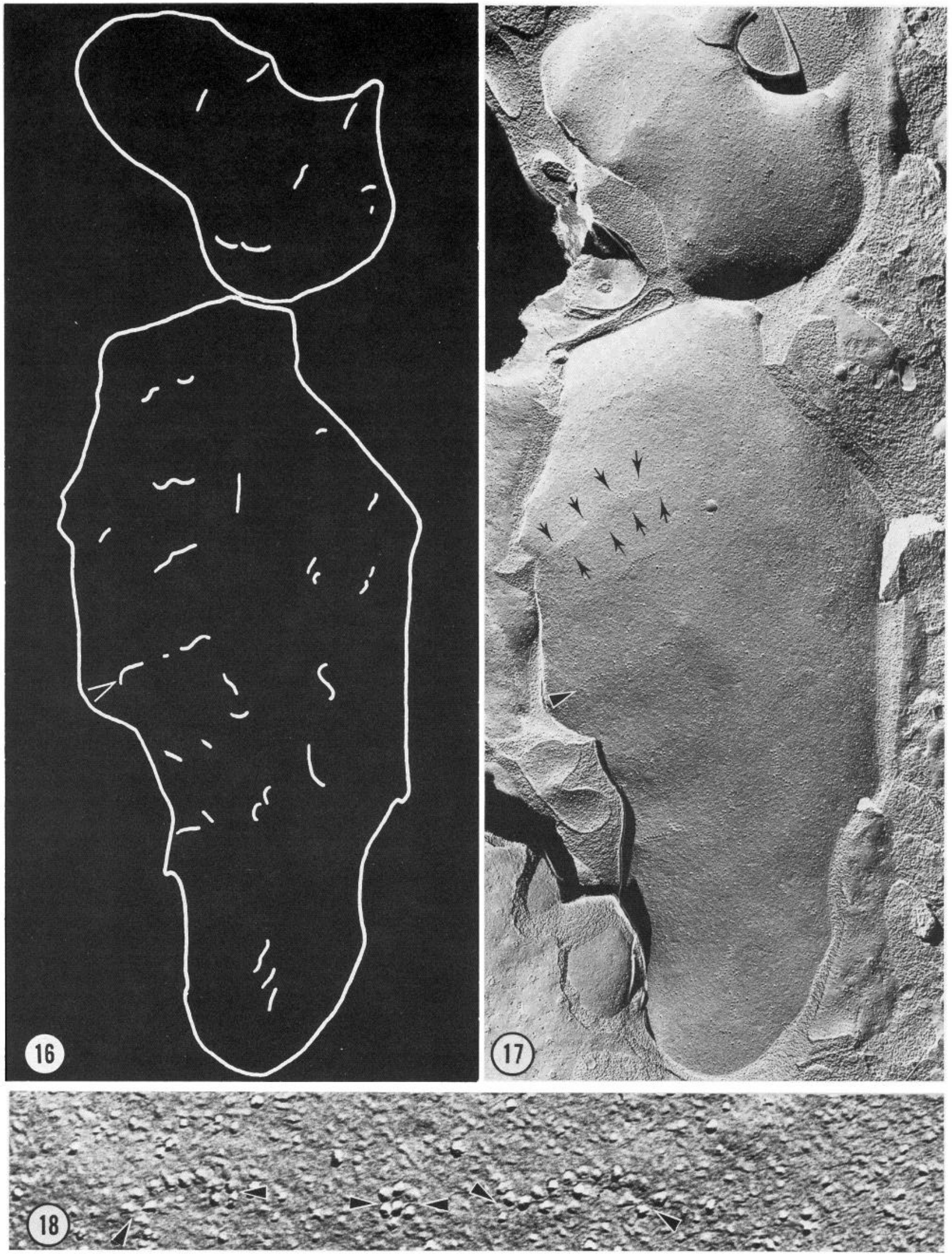

Figures 16-18 

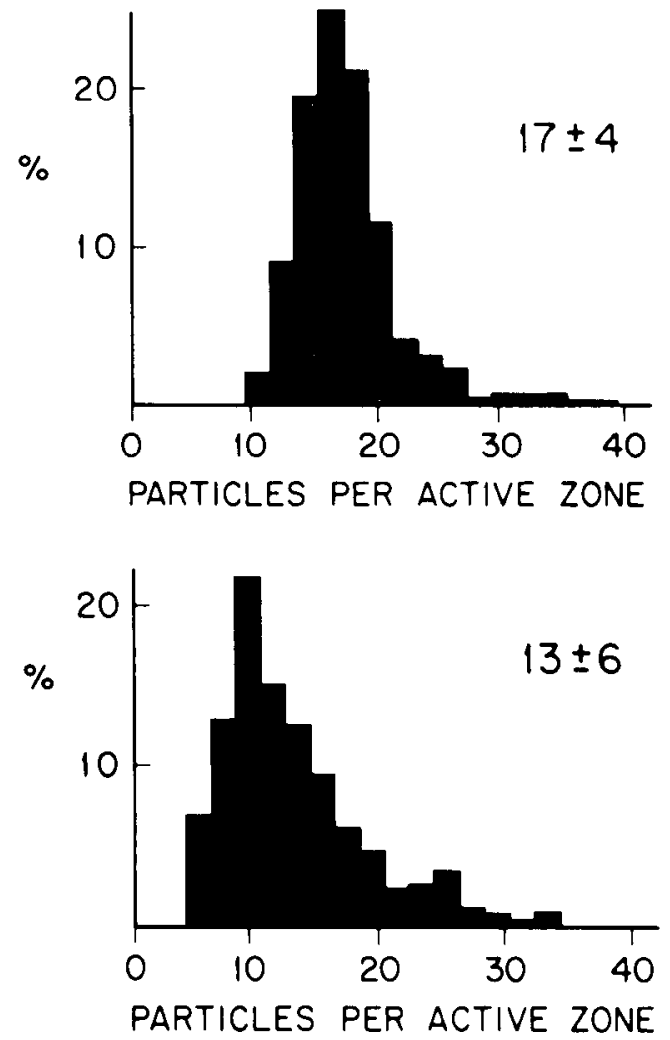

Figure 19. Comparison of the numbers of intramembrane particle clusters of particle rows, comprising active zones, on twitch (top) and tonic (bottom) fibers. The particles are divided evenly among four rows on twitch fibers but only among two on tonic fibers, so that the rows in tonic muscles are necessarily longer and also appear to be more variable in length.

face at the synaptic cleft. The axon terminal $E$ face, lying adjacent to the muscle, contains furrows or hollows which correspond to the $P$ face ridges. The terminals sit in depressions in the muscle surface which are bounded by a rim of sarcolemma (Fig. 22). When the plane of fracture exposes the sarcolemma under a synaptic terminal on a tonic muscle fiber, the resulting fracture sometimes uncovers en face views of the shallow junctional folds beneath the axon terminal (Fig. 23). The organization and spacing of the troughs between the folds is in register with furrows in the $E$ (exoplasmic) face of terminal boutons (Figs. 22 and 23).

Planes of fracture through postsynaptic folds of twitch fibers were not obtained, presumably because they tended to be raised above the surface of the muscle and therefore were seldom in the plane of fracture. However, occasional fractures exposed enough of these folds to indicate that the particles on the tops of the folds resemble those on tonic fibers. Most of the intramembrane particles on the $P$ face of the postsynaptic membrane in tonic fibers lie on the crests of the junctional folds (Figs. 22 to 24). This distribution corresponds to the distribution of acetylcholine receptors observed in other systems and may represent the portion of the acetylcholine receptor which spans the lipid bilayer (Rash and Ellisman, 1974; Daniels and Vogel, 1975; Fertuck and Salpeter, 1976; Rash et al., 1978; Heuser and Salpeter, 1979; Hirokawa and Heuser, 1982).

Although the troughs between the junctional folds on tonic fibers are sparsely populated with intramembrane particles, they are punctuated with specialized particle aggregates (Fig. 24) known as assemblies in the brain or orthogonal arrays with square lattice spacing in muscle (Rash et al., 1973; Landis and Reese, 1974; Rash and Ellisman, 1974). However, they are not confined to the synapse and also appear in the $\mathrm{P}$ face of the sarcolemma in extrasynaptic regions. Assemblies on twitch fibers extend onto the sides of the junctional folds but are segregated from the receptor-rich regions at the crests of the folds.

\section{Discussion}

The Anolis intercostal muscles provide a favorable preparation for structural investigations of neuromuscular synapses. Their thinness enhances the accessibility of conventional and histochemical stains to pre- and postsynaptic structures and reduces optical interference from overlapping muscle fibers in whole mount preparations examined with the light microscope. The resulting unambiguous localization of individual synapses in whole mounts facilitates ultrastructural studies on identified neuromuscular junctions. The superficial location of synapses on these muscles also makes them ideal for studies depending on direct freezing (e.g., Heuser et al., 1976; Walrond and Reese, 1981). Caudal rib pairs can be selected, if needed, to minimize the proportion of tonic fibers, but the present study takes advantage of the mixture of fast and slow fibers in the more rostral muscles to define differences in the shapes as well as the intramembrane organization of axon terminals on twitch and tonic muscle fibers.

Innervation of intercostal muscles. Nerves course along the rostral rib of each intercostal muscle and send branches onto its surface. A single axon process terminates on one type of muscle fiber, whereas a second type is innervated by multiple axon processes. Our methods did not allow differentiation of true polyneuronal innervation from innervation by multiple branches of the same axon, but some fibers are known to receive polyneuronal innervation in lizard scalenus muscles (Vaughn and Proske, 1967; Proske and Vaughn, 1968). These multiply innervated fibers do not conduct action potentials and are therefore tonic (Proske and Vaughn, 1968; Ridge, 1971; Morgan and Proske, 1984), whereas the singly innervated scalenus fibers have true action potentials and are therefore of the twitch type. These observations led us to identify tentatively the singly innervated fibers in whole mounts of lizard intercostal muscles as twitch and the multiply innervated fibers as tonic.

The lizard intercostal muscles show many similaritics to twitch and tonic fibers in the snake costocutaneous muscle (Hess, 1965; Ridge, 1971; Morgan and Proske, 1984). Thin sections of lizard intercostal muscles show that synaptic boutons on singly innervated fibers are nearly enveloped by deep junctional folds, whereas boutons on diffusely innervated fibers lie in sarcolemmal depressions on shallow and irregular junctional folds. The organization of myofibrils and sarcoplasmic reticulum in these two fiber types is also consistent with characterizing them as twitch and tonic, respectively (Hess, 1965; Page, 1965; Morgan and Proske, 1984). We were then able to rely on the characteristic differences in the distributions and shapes of postsynaptic folds as criteria to distinguish terminals on twitch and tonic fibers in replicas of freeze-fractured muscles.

Organization of presynaptic active zones. The protoplasmic fracture faces of terminals on twitch fibers are characterized by paired linear arrays of intramembrane particles. Each array contains two particle rows which lie perpendicular to shallow ridges on the nerve terminal membrane. Comparable arrays in terminals on tonic fibers consist of a single linear particle array of two particle rows which lie parallel to the axis of an axolemmal ridge (Fig. 25). Vesicle openings induced by potassium stimulation appear between the two paralle linear particle arrays at terminals on twitch fibers, but beside the single linear particle array at terminals on tonic fibers. The location of synaptic vesicle openings next to the particle arrays at terminals on both types of muscle fiber leads us to refer to these regions of the axolemma as the active zones for synaptic vesicle opening (Couteaux and Pecot-Deschavassine, 1970; Heuser and Reese, 1977).

Active zones are more concentrated in the membranes of terminals facing twitch fibers, but their total number is not significantly different in axon terminals on the two types of muscle fiber because the total area of terminal facing a tonic fiber is greater (Table 1). Although the intramembrane particle arrays defining active zones are arranged differently at twitch and tonic muscle fibers, the total numbers of intramembrane particles per active zone are similar (twitch, $17 \pm 4$; tonic, $13 \pm 6$ ). Therefore, there are no differences 


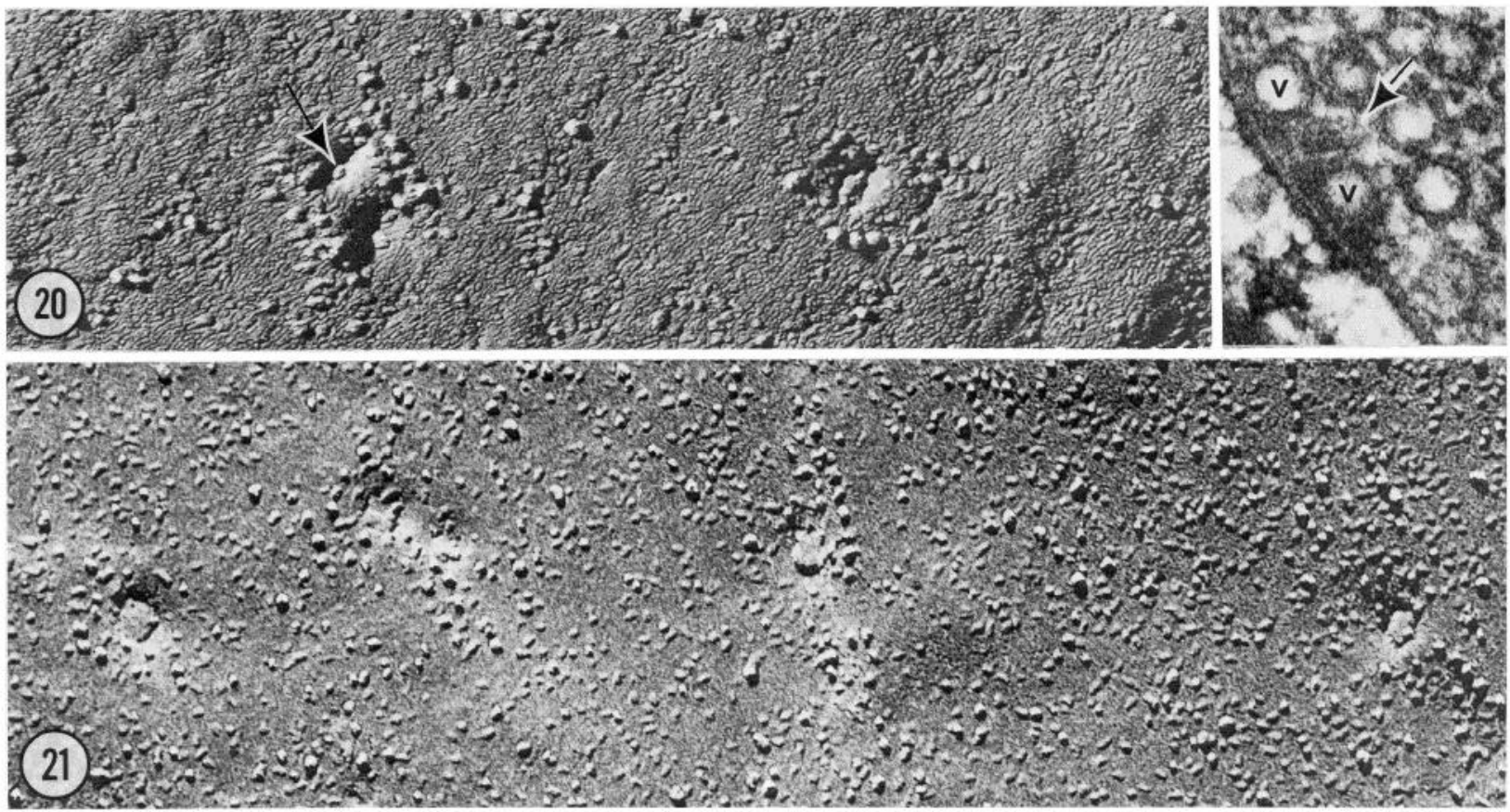

Figure 20. Large pits on the $\mathrm{P}$ face of a presynaptic terminal on a twitch fiber. One and sometimes two exocytotic pits occur between the paired linear particle arrays of $P$ face particles when preparations are fixed in the presence of increased potassium; they are therefore assumed to be openings of synaptic vesicles. An intramembrane particle (arrow) appears at the base of vesicle openings which are not cross-fractured. Magnification $\times 150,000$. The inset shows a thin section through a fast-frozen, freeze-substituted presynaptic complex. A dense projection (arrow) separates two vesicles ( $v$ ) closely apposed to the plasmalemma. The position of the density correlates with the bare region separating the exocytotic pits seen in freeze-fracture. Magnification $\times 150,000$

Figure 21. Synaptic vesicle openings next to particle arrays on the $\mathrm{P}$ face of a presynaptic terminal on a tonic fiber stimulated with potassium. Here, single vesicle openings characteristically appear beside the single linear array of particles. Magnification $\times 150,000$.

TABLE I

Measurements of presynaptic membranes of twitch and tonic intercostal muscles

\begin{tabular}{|c|c|c|}
\hline Parameter Measured & Twitch & Tonic \\
\hline Particles per active zone ${ }^{a}$ & $17 \pm 4^{b}$ & $13 \pm 6$ \\
\hline $\begin{array}{l}\text { Distance between particles in array } \\
(\mathrm{nm})^{a}\end{array}$ & $17.3 \pm 2.2$ & $18.2 \pm 1.8$ \\
\hline $\begin{array}{l}\text { Distance between particles in row } \\
(\mathrm{nm})^{\mathrm{a}}\end{array}$ & $16.7 \pm 2.4$ & $16.1 \pm 3.6$ \\
\hline $\begin{array}{l}\text { Distance between paired arrays } \\
\qquad(\mathrm{nm})^{a}\end{array}$ & $37.5 \pm 3.3$ & \\
\hline Active zones per $\mu \mathrm{m}^{2 a}$ & $6.3 \pm 1.8$ & $3.4 \pm 1.1$ \\
\hline Muscle area covered by terminal ${ }^{a}$ & $210 \pm 66$ & $403 \pm 120$ \\
\hline Area of active zone region $\left(\mu \mathrm{m}^{2}\right)^{c}$ & $380 \pm 141$ & $520 \pm 260$ \\
\hline $\begin{array}{l}\text { Number of active zones per termi- } \\
\text { nal }^{d}\end{array}$ & $2,400 \pm 1,100$ & $1,800 \pm 1,000$ \\
\hline Total active zone vesicles & 5,000 & 5,000 or $10,000^{\circ}$ \\
\hline $\begin{array}{l}\text { Total active zone particles }(\times \\
1,000)\end{array}$ & $40.1 \pm 16.8$ & $23.4 \pm 17.0$ \\
\hline
\end{tabular}

${ }^{a}$ By direct measurement.

${ }^{\circ}$ Values are mean $\pm \mathrm{SD}$.

'The area of the active zone region was obtained by multiplying the muscle area covered by terminal times a correction factor (see the text).

The standard deviations for calculated means were obtained from the formulae:

$g=\left(x_{1}\right)\left(x_{2}\right)\left(x_{3}\right), \operatorname{Var}(g)=\left(x_{2} x_{3}\right)^{2} s_{1}{ }^{2}+\left(x_{1} x_{3}\right)^{2} s_{2}^{2}+\left(x_{1} x_{2}\right)^{2} s_{3}{ }^{2}$, and SD $(g)$ $=\sqrt{\operatorname{Var}(g)}$.

${ }^{a}$ The number of active zones per terminal was calculated by multiplying the area of the active zone region times the active zones per square micrometer.

${ }^{e}$ We could not determine whether vesicles line up on one or both sides of the particle row. in the number of active zone vesicles which could explain how terminals on twitch fibers release at least 10 times as many quanta per action potential as terminals on tonic fibers (Proske and Vaughn, 1968; Ridge, 1971; Dionne and Parsons, 1981). Presynaptic active zones facing tonic fibers are more spread out over the sarcolemmal surface than those facing twitch fibers. This difference in the distribution of active zones may reflect the fact that tonic fibers depend on passive spread of synaptic currents over their sarcolemma to produce graded contractions.

Active zone organization and quantal content. The number of quanta released by an action potential in lizard twitch axon terminals is not known, but similar synapses on snake costocutaneous muscle release about 300 quanta (Hartzell et al., 1975). If lizard axon terminals release a similar number of quanta per nerve action potential, on the order of $6.0 \%$ of the active zone vesicles must open (Table I). This figure assumes that two vesicles are poised for release at each twitch active zone and that all of these vesicles are releasable. However, this is not to say that all active zone vesicles have the same probability of release at any one moment (Heuser et al., 1979).

Even though the vesicles associated with the active zone may not at any given moment be a homogeneous pool with respect to their probability of release, some structural features of the active zone might be related to their overall probability of release. Axon terminals on twitch and tonic muscle fibers have a similar number of active zones and presumably a similar number of active zone vesicles available for release. Therefore, active zone vesicles at tonic fibers must have a lower probability of opening than those at twitch fibers since an action potential releases fewer than 20 quanta from a terminal on a tonic fiber (Proske and Vaughn, 1968; Ridge, 1971; Dionne and Parsons, 1981). Assuming that every available release site contains an active zone vesicle, a presynaptic action potential would open no more than $0.4 \%$ (20 of 5000 ) of the active zone 

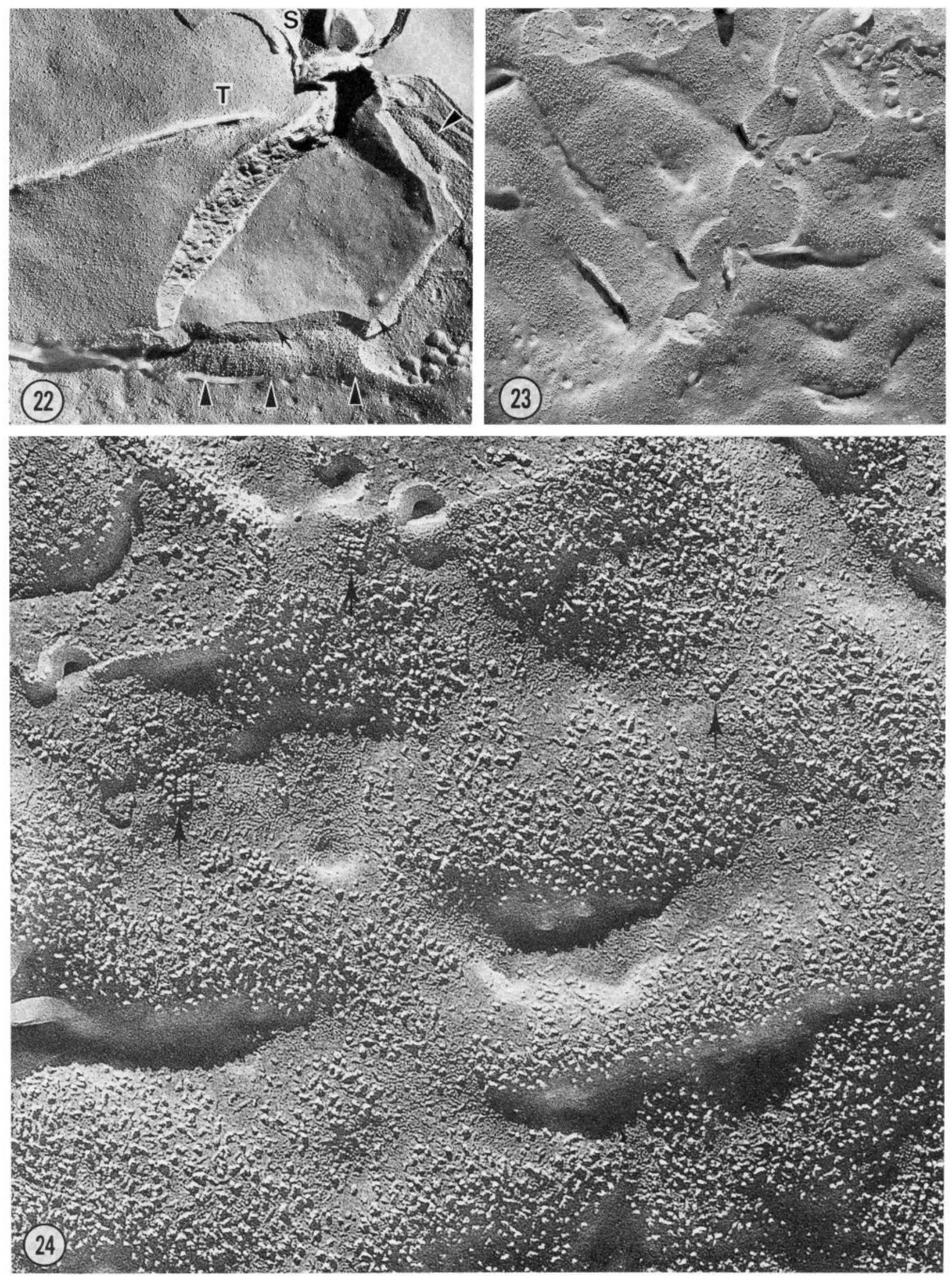

Figure 22. Subcellular organization of the neuromuscular synapse on tonic fibers. The protoplasmic leaflet of the axon terminal $(T)$ underlying the Schwann cell $(S)$ contains numerous $\mathrm{P}$ face particles but is free of the specialized particle aggregates found on the protoplasmic leaflet facing the postsynaptic cell (cf. Fig. 16). The axon terminal $E$ face adjacent to the synaptic cleft contains hollows (small arrows) which correspond to $P$ face ridges. Intermittent linear arrays of $E$ face pits reside in these furrows. A ridge in the sarcolemma (arrowheads) forms the edge of a cup in which the terminal sits. Magnification $X$ 40,000 .

Figure 23. Protoplasmic leaflet of the postsynaptic membrane which originally lay under a terminal on this tonic fiber. Particle-free valleys run between particle-rich but shallow junctional folds. The size and arrangement of the ridges with the linear particle arrays on the presynaptic terminal (see Fig. 16) correspond to the size and spacing of these postsynaptic infoldings. Magnification $\times 40,000$.

Figure 24. Enlargement from Figure 23 showing that the particle-poor regions in the infoldings of tonic fibers contain orthogonal particle assemblies (arrows). Single large particles thought to be associated with the acetylcholine receptors mark the crests of the outfoldings. Magnification $\times 150,000$. 


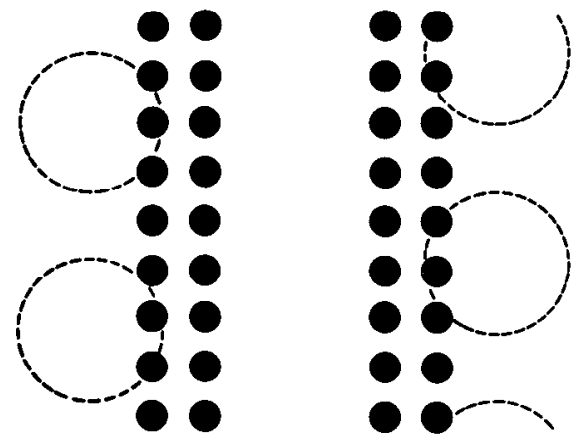

FROG TWITCH
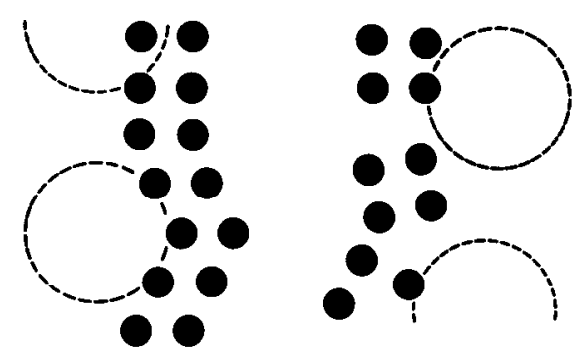

FROG TONIC

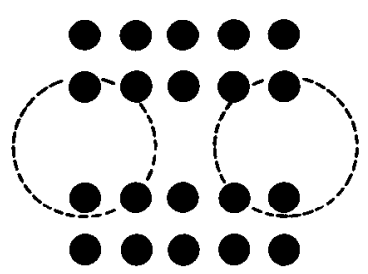

LIZARD TWITCH

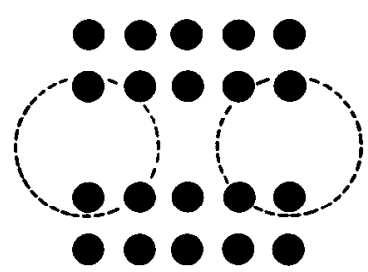

RAT TWITCH

(fast and slow)

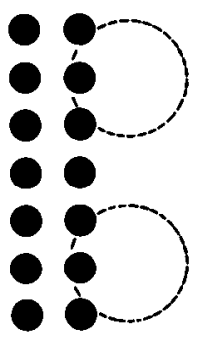

LIZARD TONIC

Figure 25. Scale drawing of active zones at axon terminals from three vertebrate classes. Synaptic vesicles (large open circles) are associated with the presynaptic membrane near large intramembrane particles (small solid circles). For each active zone, a shallow presynaptic ridge lies over the gap between folds in the sarcolemma. In this figure, the ridge runs along the vertical axis of the page. The distance between the vesicles in terminals on lizard twitch fibers is not known precisely, but freeze-fracture views of vesicle openings indicate that it may be smaller than in the frog (Fig. 20 and Heuser et al., 1979). For active zones on nerve terminals on rat muscles (Ellisman et al., 1976), the distance between vesicles was assumed to be the same as in lizard twitch terminals. We could not be sure that vesicles in lizard tonic terminals open only on one side of the single linear particle array, although we found no instances where vesicle openings appeared on both sides. The spacing of vesicles at active zones on terminals in frog and lizard tonic muscles is not known, but was assumed to be the same as that in frog twitch muscle. The axon terminals on frog tonic fibers have active zones consisting of two intermittent linear particle arrays (Verma and Reese, 1984). During mammalian evolution, multiple innervation has been virtually abandoned, and tonic muscle fibers have been replaced by focally innervated slow twitch fibers (l less, 1970; Morgan and Proske, 1984). Scale bar, $20 \mathrm{~nm}$.

vesicles facing tonic fibers as compared to $6.0 \%$ (300 of 5000$)$ of those facing twitch fibers.

Even though the number of active zone particles per active zone vesicle is not significantly different at twitch and tonic fibers (Table 1), due to their arrangement, there is a clear difference in the number of particles near each active zone vesicle. Twice as many active zone particles lie beneath each active zone vesicle at twitch fibers as at tonic fibers, because at twitch fibers the active zone vesicles are flanked by two linear particle arrays, whereas at tonic fibers the active zone vesicles lie beside a single linear particle array as diagrammed in Figure 25. Thus, the number of active zone particles near an active zone vesicle appears to set the probability that it will be opened by an action potential, and it becomes possible to refer to these sites as high or low oulput aclive cones. Termirials on twitch fibers have high output active zones and are therefore high output terminals; those on tonic fibers have low output active zones and are therefore low output terminals.

Comparable differences in nerve terminal structure, which correlate with muscle fiber type, also exist in certain invertebrates. In lobsters, a single excitatory axon innervates both the proximal and distal muscle fiber bundles in the distal accessory flexor muscle. However, a presynaptic action potential releases 3 to 4 times more quanta from terminals innervating the distal muscle fiber bundle (Meiss and Govind, 1979). The presynaptic densities at these high output synapses are larger and cover a greater proportion of the total synaptic area than those at low output synapses, but the differences in size were small compared to the differences in the numbers of quanta released (Govind and Meiss, 1979; Govind et al., 1982; Atwood and Marin, 1983). At the neuromuscular junction of a crab, there is no simple linear relationship between quantal release and active zone size as seen in thin sections (Atwood and Marin, 1983). Freeze-fracture views of these high and low output synapses are needed to determine the relationship between the distribution of active zone particles, active zone vesicles, and the probability of quantal transmitter release.

The changes in the arrangement of active zone particles during vertebrate evolution also suggests a relationship between the concentration of the particles near an active zone vesicle and the probability that this vesicle will open in response to an action potential (Fig. 25). In axon terminals on twitch fibers, the presynaptic action potential must mobilize sufficient neurotransmitter to bring the muscle fiber to threshold. Although terminals on twitch fibers in frog muscle contain more active zone vesicles $(20,000)$ than nerve terminals in lizard muscle $(5,000)$, action potentials release similar numbers of quanta from the two types of terminal (Hartzell et al., 1975; Katz and Miledi, 1979). The mobilization of an equal number of quanta from the smaller pool in the lizard could result from the higher concentration of active zone particles near each active zone vesicle. A similar consideration applies to mammalian slow and fast twitch muscle fibers which also have their active zone vesicles flanked by two linear particle arrays (Ellisman et al., 1976).

Active zone particles as putative calcium channels. At the squid giant synapse, the $200-\mu$ sec delay between calcium influx and transmitter release has been interpreted as meaning that the calcium channels involved in release are no more than 40 to $100 \mathrm{~nm}$ from the active zone because this is the maximum distance calcium can 
diffuse during the delay (Llinás et al., 1981, 1982; Reichardt and Kelly, 1983). Recently developed models indicate that the initial calcium channel openings alter the internal free calcium concentration only in the volume of cytoplasm near the site of influx (Chad and Eckert, 1984; Simon et al., 1984), providing additional evidence that the calcium channels responsible for transmitter release are located adjacent to the active zone vesicles.

The relationship between the distribution of particles near active zone vesicles and the level of quantal release is consistent with the idea that the active zone particles might be the calcium channels which initiate transmitter release (Heuser et al., 1974; Pumplin et al., 1981). If differences in the probability of active zone vesicles opening at twitch and tonic fibers depended directly on the concentration of active zone particles, the ratio between the number of quanta released at twitch and tonic fibers should be less than $2: 1$. However, as noted above, this ratio is actually closer to $10: 1$. The disparity between the number of particles near each active zone vesicle and the number of quanta released could still be consistent with the idea that the particles are the calcium channels that trigger transmitter release if the number of vesicles opening were not linearly related to the amount of local calcium influx. It is not possible to say whether this is true for lizard terminals, but it is feasible that only a fraction of the calcium channels open during an action potential (Pumplin et al., 1981) and that a requisite number of channels must open before vesicle opening becomes likely. It follows from simple binomial statistics that the effect on the probability of vesicle opening of increasing the number of channels near an active zone vesicle would be far greater than predicted by a simple proportional relationship. ${ }^{3}$

This argument requires that simultaneously opening the requisite number of channels overcomes a threshold at which the probability of vesicle opening suddenly and dramatically increases. To reach this threshold, several channels in addition to those beneath the vesicle would need to open simultaneously. The extremely localized effect of incoming calcium on quantal release means that nearby channels would be effective only when acting in concert with channels beneath the vesicle. A threshold number of channel openings could reduce the probability of random transmitter release caused by the spontaneous opening of a single calcium channel, yet ensure an adequately high probability of release during depolarization when quantal release exceeds resting levels by several orders of magnitude (Llinás and Heuser, 1977; Llinás, 1979).

The arrangement of active zone particles found in axon terminals on lizard and mammalian twitch fibers can be interpreted as an evolutionary step directing more calcium channels at each active zone vesicle to obtain much higher probabilities of transmitter release. Indeed, the similar arrangement of active zone particles in these functionally homologous axon terminals (Fig. 25) indicates a structural feature of active zone organization which might influence the probability that an associated synaptic vesicle will open. This conclusion supports the idea that the active zone particles are the calcium channels which couple the action potential to vesicle opening.

\footnotetext{
${ }^{3}$ For example, if one-third of the calcium channels are opened randomly and independently by each action potential (Pumplin et al., 1981), and there are 14 channels close enough to an active zone vesicle to affect its probability of release, then the probability of release of 0.06 characteristic of twitch terminals would require that eight or more calcium channels open. At a terminal on a tonic fiber, where there would be only 10 calcium channels close enough to affect an active zone vesicle, the probability of eight channels opening would be 0.004 , close to the actual probability of release at these terminals. These numbers are chosen as representative of a wide range of values where the principle would apply that increasing the number of calcium channels near an active zone vesicle would result in a disproportionately large increase in its probability of opening; we do not know what actual values apply to the lizard terminal.
}

\section{References}

Akert, K., and C. Sandri (1968) An electron-microscopic study of zinc-iodide osmium impregnation of neurons. I. Stainiriy of synaptic vesicles at cholinergic junctions. Brain Res. 7: 286-295.

Akert, K., K. Pfenninger, C. Sandri, and H. Moor (1972) Freeze-etching and cytochemistry of vesicles and membrane complexes in synapses of the central nervous system. In Structure and Function of Synapses, G. D. Pappas and D. P. Purpura, eds., pp. 67-86, Raven Press, New York.

Atwood, H. L., and L. Marin (1983) Ultrastructure of synapses with different transmitter-releasing characteristics on motor axon terminals of a crab, Hyas areneas. Cell Tissue Res. 231: 103-115.

Ceccarelli, B., F. Grohovaz, and W. P. Hurlbut (1979) Freeze fracture studies of frog neuromuscular junctions during intense release of neurotransmitter. II. Effects of electrical stimulation and high potassium. J. Cell Biol. 81: $178-192$.

Chad, J. E., and R. Eckert (1984) Calcium domains associated with individual channels can account for anomalous voltage relations of Ca-dependent responses. Biophys. J. 45: 993-999.

Cohen, S. A., and D. W. Pumplin (1979) Clusters of intramembrane particles associated with binding sites for [alpha] bungarotoxin in cultured chick myotubes. J. Cell Biol. 82: 494-516.

Couteaux, R., and M. Pecot-Deschavassine (1970) Vesicules synaptiques et poches au niveau des zones actives de la jonction neuromusculaire. Compt. Rend. 271: 2346-2349.

Couteaux, R., and M. Pecot-Deschavassine (1974) Les zones specialisées des membranes presynaptiques. C. R. Acad. Sci. Paris 280: 299-301.

Daniels, M. P., and Z. Vogel (1975) Immunoperoxidase staining of [alpha] bungarotoxin binding sites in muscle endplates shows distribution of acetylcholine receptors. Nature 254: 339-341

Dickinson-Nelson, A., and T. S. Reese (1983) Structural changes during transmitter release at synapses in the frog sympathetic ganglion. $\mathrm{J}$. Neurosci. 3: 42-52.

Dionne, V. E., and R. L. Parsons (1981) Characteristics of the acetylcholine operated channel at twitch and slow fiber neuromuscular junctions of the garter snake. J. Physiol. (Lond.) 310: 145-158.

Ellisman, M. H., J. E. Rash, L. A. Straehlein, and K. R. Porter (1976) Studies of excitable membranes. II. A comparison of specialization at neuromuscular junctions and nonjunctional sarcolemmas of mammalian fast and slow twitch muscle fibers. J. Cell Biol. 68: 752-774.

Fertuck, H. C., and M. M. Salpeter (1976) Quantitation of junctional and extra-junctional acetylcholine receptors by electron microscope autoradiography after ${ }^{125}$-[alpha]-bungarotoxin binding at mouse neuromuscular junctions. J. Cell Biol. 69: 144-158.

Franzini-Armstrong, C. (1976) Freeze-fracture of excitatory and inhibitory synapses in crayfish neuromuscular junctions. J. Microsc. Biol. Cell. 25 217-222.

Govind, C. K., and D. E. Meiss (1979) Quantitative comparison of low- and high-output neuromuscular synapses from a motorneuron of the lobster (Homarus americanus). Cell Tissue Res. 198: 455-463.

Govind, C. K., D. E. Meiss, and J. Pearce (1982) Differentiation of identifiable lobster neuromuscular synapses during development. J. Neurocytol. 11: 235-247.

Hartzell, C. H., S. W. Kuffler, and D. Yoshikami (1975) Post-synaptic potentiation: Interaction between quanta of acetylcholine at the skeletal neuromuscular synapse. J. Physiol. (Lond.) 251: 427-463.

Hess, A. (1965) The sarcoplasmic reticulum, the T system, and the motor terminals of slow and twitch muscle fibers in the garter snake. J. Cell Biol. 26: 467-476.

Hess, A. (1970) Vertebrate slow muscle fibers. Physiol. Rev. 50: 40-62.

Heuser, J. E., and T. S. Reese (1973) Evidence for recycling of synaptic vesicle membrane during transmitter release at the frog neuromuscular junction. J. Cell Biol. 57: 315-344.

Heuser, J. E., and T. S. Reese (1977) The structure of the synapse. In Handbook of Physiology, Section 1: The Nervous System, Vol. 1: Cellular Biology of Neurons, E. R. Kandel, ed., pp. 261-294, American Physiological Society, Bethesda, MD.

Heuser, J. E., and T. S. Reese (1981) Structural changes following transmitter release at the frog neuromuscular junction. J. Cell Biol. 88: 564-580.

Heuser, J. E., and S. R. Salpeter (1979) Organization of acetylcholine receptors in quick-frozen, deep-etched, and rotary-replicated Torpedo postsynaptic membrane. J. Cell Biol. 82: 150-173.

Heuser, J. E., T. S. Reese, and D. M. D. Landis (1974) Functional changes in frog neuromuscular junctions studied with freeze-fracture. J. Neurocytol. 3: 109-131.

Heuser, J. E., T. S. Reese, and D. M. D. Landis (1976) Preservation of 
synaptic structure by rapid freezing. Cold Spring Harbor Symp. Quant. Biol. 40: 17-24.

Heuser, J. E., T. S. Reese, M. J. Dennis, Y. Jan, L. Jan, and L. Evans (1979) Synaptic vesicle exocytosis captured by quick freezing and correlated with quantal transmitter release. J. Cell Biol. 81: 275-300.

Hirokawa, N., and J. E. Heuser (1982) Internal and external differentiations of the postsynaptic membrane at the neuromuscular junction. J. Neurocytol. 11: 487-510.

Katz., B., and R. Miledi (1979) Fstimates of quantal content during chemical potentiation of transmitter release. Proc. R. Soc. Lond. (Biol.) 205: 369378.

Landis, D. M. D., and T. S. Reese (1974) Arrays of particles in freezefractured astrocyte membranes. J. Cell Biol. 60: 316-320.

Llinás, R. (1979) The role of calcium in neuronal function. In The Neurosciences Fourth Study Program, F. O. Schmitt and F. G. Worden, eds., pp. 555-571, MIT Press, Cambridge, MA.

Llinás, R., and J. R. Heuser (1977) Depolarization-release coupling systems in neurons. Neurosci. Res. Program Bull. 15: 557-687.

Llinás, R., I. Z. Steinberg, and K. Walton (1981) Relationship between presynaptic calcium current and postsynaptic potential in squid giant synapse. Biophys. J. 33: 323-351.

Llinás, R., M. Sugimori, and S. M. Simon (1982) Transmission by presynaptic spike-like dipolarizations in the squid giant synapse. Proc. Natl. Acad. Sci. U. S. A. 79: 2415-2419

McMahan, U. J., and S. W. Kuffler (1971) Visual identification of synaptic boutons on living ganglion cells and of varicosities in postganglionic axons in the heart of the frog. Proc. R. Soc. Lond. (Biol.) 177: 485-508.

Meiss, D. E., and C. K. Govind (1979) Regional differentiation of neuromuscular synapses in a lobster receptor muscle. J. Exp. Biol. 79: 99-114.

Morgan, D. L., and U. Proske (1984) Vertebrate slow muscle: Its structure, pattern of innevation, and mechanical properties. Physiol Rev. 64: 103169.

Page, S. G. (1965) A comparison of fine structures of frog slow and twitch muscle fibers. J. Cell Biol. 26: 477-497.

Peper, K., F. Dryer, C. Sandri, K. Akert, and H. Moor (1974) Structure and ultrastructure of the frog motor endplate: A freeze-etching study. Cell Tissue Res. 149: 437-455.

Proske, U., and P. Vaughn (1968) Histological and electrophysiological investigation of lizard skeletal muscle. J. Physiol (Lond.) 199: 495-509.
Pumplin, D. M., and T. S. Reese (1978) Membrane ultrastructure of the giant synapse of the squid Loligo pealei. Neuroscience 3: 685-696.

Pumplin, D. W., T. S. Reese, and R. Llinás (1981) Are the presynaptic active zone particles the calcium channels? Proc. Natl. Acad. Sci. U. S. A. 78 : 7210-7214.

Rash, J. E., and M. H. Ellisman (1974) Studies of excitable membranes. I. Macromolecular specialization of the neuromuscular junction and the nonjunctional sarcolemma. J. Cell Biol. 63: 567-586.

Rash, J. E., M. H. Ellisman, and L. A. Staehelin (1973) Freeze-cleaved neuromuscular junctions: Macromolecular architecture of post synaptic membranes of normal versus denervated muscle. J. Cell Biol. 59: 280a

Rash, J. E., C. S. Hudson, and M. H. Ellisman (1978) Ultrastructure of acetylcholine receptors at the mammalian neuromuscular junction. In Cell Membrane Receptors for Drugs and Hormones: A Multidisciplinary Approach, L. Bolis and R. W. Straub, eds., pp. 47-68, Raven Press, New York.

Reichardt, L. F., and R. B. Kelly (1983) A molecular description of nerve terminal function. Annu. Rev. Biochem. 52: 871-926

Rheuben, M. B., and T. S. Reese (1978) Three dimensional structure and membrane specializations of moth excitatory neuromuscular synapse. J. Ultrastruct. Res. 65: 65-111.

Ridge, R. M. A. P. (1971) Different types of extrafusal muscle fibers in snake costo-cutaneous muscles. J. Physiol. (Lond.) 217: 393-418.

Simon, S. M., M. Sugimori, and R. Llinás (1984) Modeling of submembraneous calcium-concentration changes and their relation to rate of presynaptic transmitter release in the squid giant synapse. Biophys. J. 45: 264a.

Tsuji, S. (1974) On the chemical basis of thiocholine methods for demonstration of acetylcholinesterase activities. Histochemistry 42: 99-110.

Vaughn, P., and U. Proske (1967) Histological and physiological studies on single and multiple innervated muscle fibers of the lizard. Aust. J. Exp. Biol. Med. Sci. 45: 31.

Venzin, M., C. Sandri, L. Akert, and U. R. Wyss (1977) Membrane associated particles of the presynaptic active zone in rat spinal cord: A morphometric analysis. Brain Res. 130: 393-404.

Verma, V., and T. S. Reese (1984) Structure and distribution of neuromuscular junctions on slow muscle fibers in the frog. Neuroscience 12: 647-662.

Walrond, J. P., and T. S. Reese (1981) Structural details of lizard neuromuscular junctions revealed by conventional and fast freeze cyrotechniques. Soc. Neurosci. Abstr. 7: 709.

Wernig, A. (1976) Localization of active sites in the neuromuscular junction of the frog. Brain Res. 118: 63-72. 